\title{
THE
}

UNIVERSITY

University of Rhode Island

OF RHODE ISLAND

DigitalCommons@URI

Physics Faculty Publications

Physics

8-15-1991

\section{A Dynamical Definition of Atomic Clusters}

J. Xie

University of Rhode Island

J. A. Northby

University of Rhode Island, jnorthby@uri.edu

David L. Freeman

University of Rhode Island, dfreeman@uri.edu

Follow this and additional works at: https://digitalcommons.uri.edu/phys_facpubs

Terms of Use

All rights reserved under copyright.

\section{Citation/Publisher Attribution}

Xie, J., Northby, J. A., \& Freeman, D. L. (1991). A Dynamical Definition of Atomic Clusters. Journal of Chemical Physics. 95(4), 3022-3023. doi: 10.1063/1.460908

Available at: http://dx.doi.org/10.1063/1.460908

This Article is brought to you for free and open access by the Physics at DigitalCommons@URI. It has been accepted for inclusion in Physics Faculty Publications by an authorized administrator of DigitalCommons@URI. For more information, please contact digitalcommons-group@uri.edu. 


\title{
AIP $\begin{gathered}\text { molowanat } \\ \text { chemical Physics }\end{gathered}$
}

\section{A dynamical definition of atomic clusters}

\author{
J. Xie, J. A. Northby, and David L. Freeman
}

Citation: J. Chem. Phys. 95, 3022 (1991); doi: 10.1063/1.460908

View online: http://dx.doi.org/10.1063/1.460908

View Table of Contents: http://jcp.aip.org/resource/1/JCPSA6/v95/i4

Published by the American Institute of Physics.

\section{Additional information on J. Chem. Phys.}

Journal Homepage: http://jcp.aip.org/

Journal Information: http://jcp.aip.org/about/about_the_journal

Top downloads: http://jcp.aip.org/features/most_downloaded

Information for Authors: http://jcp.aip.org/authors

\section{ADVERTISEMENT}

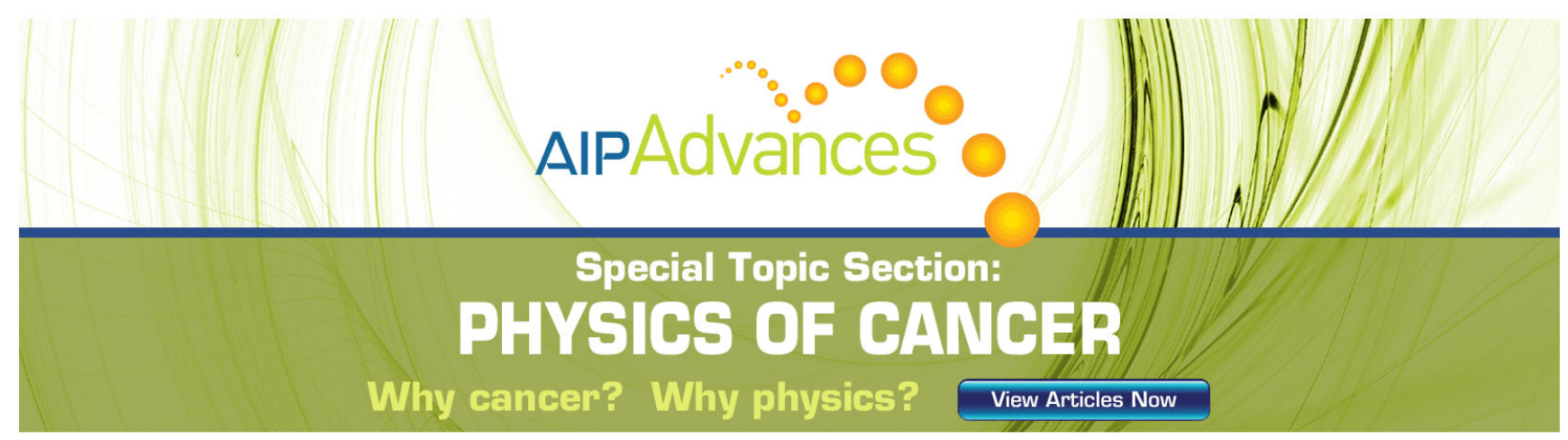




\title{
A dynamical definition of atomic clusters
}

\author{
J. Xie and J. A. Northby \\ Department of Physics, University of Rhode Island, Kingston, Rhode Island 02881 \\ David L. Freeman \\ Department of Chemistry, University of Rhode Island, Kingston, Rhode Island 02881
}

(Received 19 March 1991; accepted 7 May 1991)

The ambiguities associated with the definition of a cluster within an assembly of atoms present well-known difficulties in the numerical and theoretical study of many important areas of condensed matter science. The ambiguity arises because the assignment of an atom to a particular cluster is definition dependent. In both equilibrium statistical mechanical investigations of clusters as well as many dynamical studies of clusters, it has become common to define cluster membership in terms of the structure of the constituent atoms in configuration space. ${ }^{1-4}$

One clear difficulty with any structural based definition of cluster membership is that an atom not energetically bound to a particular cluster may be structurally assigned to a cluster. As an example, consider an atom in collision with a cluster under conditions when the monomer kinetic energy is too high for capture by the cluster. Within any structural model, the high kinetic energy atom will be considered to be part of the cluster during the time the atom is in close proximity to the cluster. Another difficulty in dynamics calculations is assigning a precise time at which an atom either joins or leaves a cluster. For example, on evaporation the lifetime of a slow atom will be much more sensitive to a defining radius for a cluster than the lifetime of a fast atom. Consequently, an improved definition of a cluster should include dynamical as well as structural information. During ongoing investigations of cluster evaporation, we have found a dynamical definition of cluster membership, which is easy to implement in molecular dynamics calculations and avoids some of the difficulties of definitions based solely on structure. Our definition of cluster membership is related to but distinct from the definition of lifetime which was used by Woodruff and Thompson. ${ }^{5}$ Since we believe our definition will have general applicability to a number of cluster processes, we present its essential features below.

One characteristic of a particle being a member of an atomic cluster is that the particle exchanges energy with the other members of the cluster, i.e., energy is constantly flowing into and out of each member atom. This flow of energy between the constituent atoms can be monitored by calculating the power flow to each atom, i.e., by examining $P_{\alpha}=d K_{\alpha} / d t$, where $t$ is the time, and $P_{\alpha}$ and $K_{\alpha}$ are, respectively, the power flow to atom $\alpha$ and its kinetic energy. For a bound atom $P_{\alpha}$ will oscillate in time in a fairly regular fashion. In contrast when atom $\alpha$ is not a member of a cluster, $P_{\alpha}$ is a monotonic function of time asymptotically approaching zero. A reasonable definition of the time of an evaporation or capture event is that point in time where the character of $P_{\alpha}$ changes between oscillatory and monotonic. Consequently we define the time of an evaporation (capture) of an atom from a cluster to be the instant of the last (first) sign reversal of the power flow to that atom. The implementation of this definition proves to be very simple in a molecular dynamics calculation. In such calculations the kinetic energy of atom $\alpha$ is calculated at each integration time step $t_{i}$ and the quantity $\Lambda_{\alpha}\left(t_{i}\right)$ $=\left[K_{\alpha}\left(t_{i+1}\right)-K_{\alpha}\left(t_{i}\right)\right]\left[K_{\alpha}\left(t_{i}\right)-K_{\alpha}\left(t_{i-1}\right)\right]$ is formed. $\Lambda_{\alpha}\left(t_{i}\right)$ will be strictly negative only if the sign of the power flow of atom $\alpha$ reverses at $t_{i}$. In other words, a power zero for atom $\alpha$ which is a member of a cluster is identified by those points in time at which $\Lambda_{\alpha}\left(t_{i}\right)$ is negative. For atoms that are not members of a cluster, $\Lambda_{\alpha}\left(t_{i}\right)$ is always positive because the power flow to the cluster asymptotically approaches zero. In actual applications in the asymptotic region when $\Lambda_{\alpha}\left(t_{i}\right)$ is very small, errors arising from computer noise can cause $\Lambda_{\alpha}\left(t_{i}\right)$ to become very slightly negative. Consequently, in practice we identify power zeros by the condition $\Lambda_{\alpha}\left(t_{i}\right)<-\epsilon$, where $\epsilon$ is a small positive constant on the order of the computer noise.

As a first example of the use of the definition described in the previous paragraph, in Fig. 1 we present the results of a classical molecular dynamics calculation of a particular trajectory for a six atom Lennard-Jones cluster. The upper curve in Fig. 1 is the cumulative number of power zeros (NP0) for each atom in the cluster as a function of reduced time, and the lower curve is the bond order of the cluster (B) as defined by Doll ${ }^{4}$ [see Eqs. (3.1) and (3.2) of Ref. 4]. We have shown the bond order as a function of time to contrast the dynamical definition with a typical structural definition. By examining the power zero portion of the curve, it is clear that an evaporation of one atom has occurred at 37.41 time units. This evaporation is also reflected in the bond order definition, but with a less obvious assignment of the time at which the evaporation occurred. It is of interest that the frequency of the power zeros is roughly the same for all atoms before the evaporation and does not change for the unevaporated atoms in the cluster after the evaporation event.

A second example is shown in Fig. 2 for a 17 atom Lennard-Jones cluster. The curve of NP0 as a function of time for atom number 8 in the cluster (the numbering is arbitrary) is typical for atoms which do not evaporate over the duration of the trajectory. In constrast atom 6 clearly evaporated at 53.55 time units. The curves for atom 5 and 11 represent dimer evaporation. This dimer evaporation, which occurred between 11 and 12 time units, is evident 

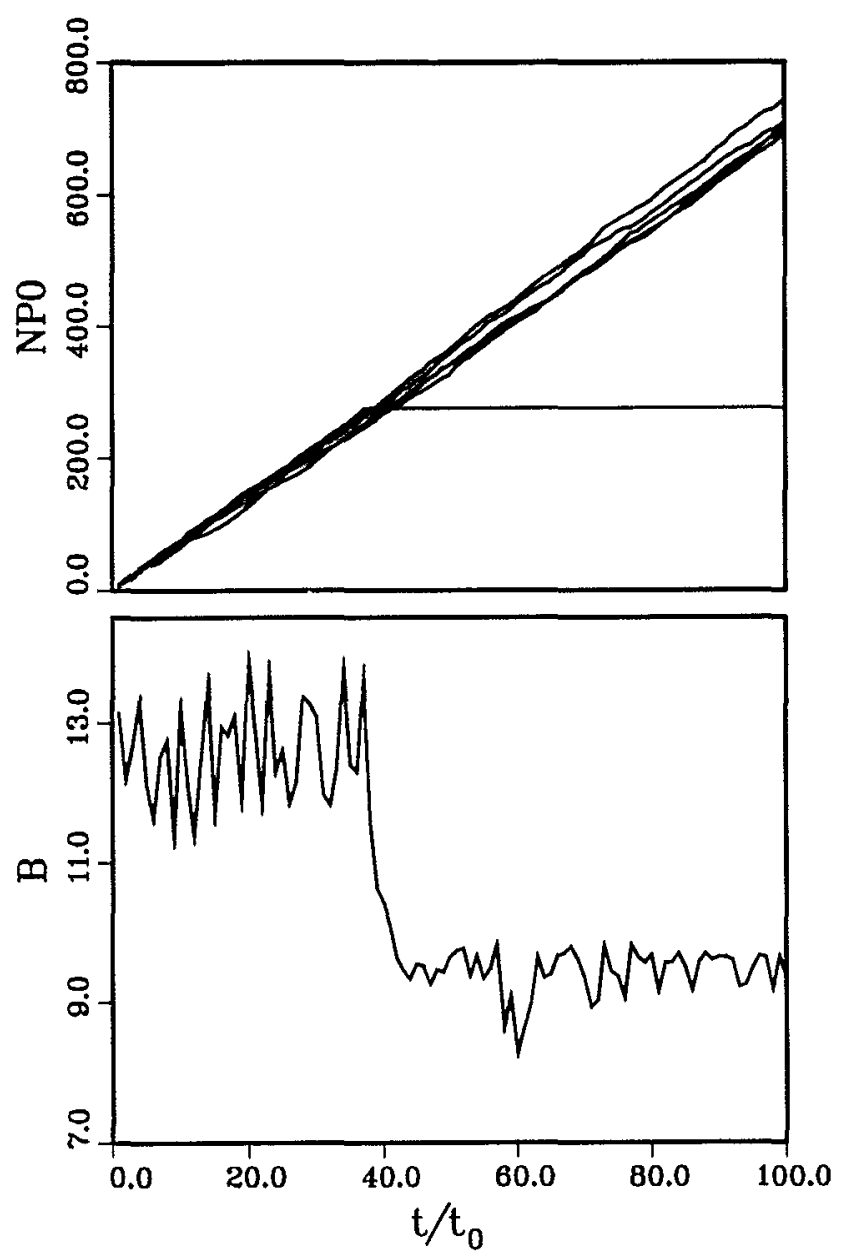

FIG. 1. The cumulative number of power zeros NPO (upper curve) and the bund order B (lower curve) for a typical trajectory for a 6 atom Lennard-Jones cluster as a function of reduced time $\left(t_{0}=2^{1 / 6} \sigma \sqrt{m / \epsilon}\right.$, where $m$ is the particle mass and $\epsilon$ and $\sigma$ are the usual Lennard-Jones parameters). The total energy for this trajectory was $-5 \epsilon$. A monomer evaporation at 37.41 time units is clearly evident.

because the slopes associated with atoms 5 and 11 are identical to each other but significantly different from the remainder of the cluster after the evaporation. It is noteworthy that such non-monomer evaporation events can be

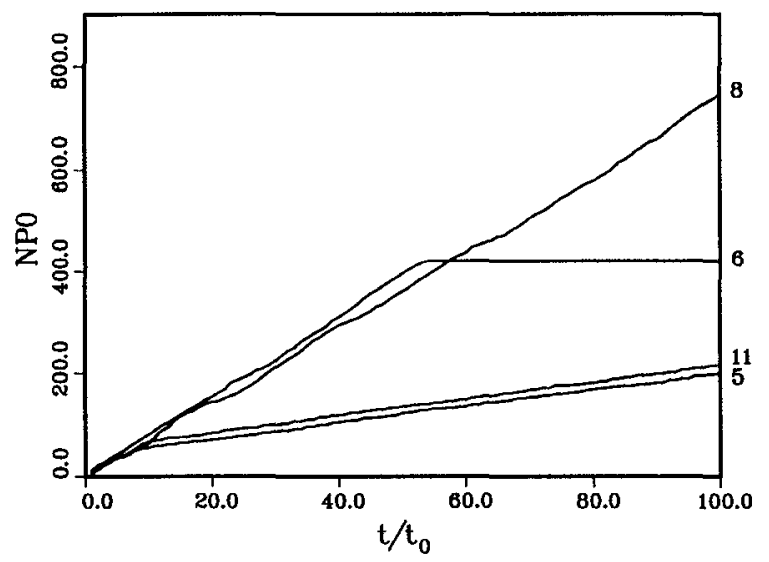

FIG. 2. The number of power zeros as a function of reduced time for selected particles from a typical 17 atom Lennard-Jones cluster trajectory. The total energy was $-15 \epsilon$. A dimer evaporation (atoms 5 and 11) occurred between 11 and 12 time units and a monomer evaporation (atom 6) occurred at 53.55 time units.

clearly identified and monitored using this method. The curves for the other atoms in the cluster have been omitted from Fig. 2 for clarity.

We have found the definition of cluster membership discussed here to be most valuable for evaporation studies when the energy is sufficiently low that fragmentation does not occur. For studies where clusters of varying sizes are present simultaneously, the power zero criterion could certainly form part of a more general definition that would include structure as well as dynamics.

Acknowledgment is made to the donors of the Petroleum Research Fund of the American Chemical Society and the National Science Foundation (Grant No. DMR 8816482) for partial support of this research.

'J. K. Lee, J. A. Barker, and F. F. Abraham, J. Chem. Phys. 58, 3166 (1973).

${ }^{2}$ F. H. Stillinger, J. Chem. Phys. 38, 1486 (1963).

${ }^{3}$ H. Reiss, A. Tabazadeh, and J. Talbot, J. Chem. Phys. 92, 1266 (1990).

${ }^{4}$ J. D. Doll, J. Chem. Phys. 74, 1074 (1981).

${ }^{5}$ S. B. Woodruff and D. L. Thompson, J. Chem. Phys. 71, 376 (1979). 